\title{
Prone positioning acute respiratory distress syndrome patients
}

\author{
Claude Guérin ${ }^{1,2,3}$ \\ ${ }^{1}$ Medical ICU, Croix Rousse Hospital, Lyon, France; ${ }^{2}$ University of Lyon, Lyon, France; ${ }^{3}$ INSERM 955, Créteil, France \\ Correspondence to: Claude Guérin. Medical ICU, Croix Rousse Hospital, 103 grande rue de la Croix Rousse 69004 Lyon, France. \\ Email: claude.guerin@chu-lyon.fr.
}

\begin{abstract}
Prone position has been used in acute respiratory distress syndrome (ARDS) patients for more than 40 years in ICU. After having demonstrated its capability to significantly improve oxygenation in a large number of patients, sometimes dramatically, this procedure has been found to prevent ventilatorinduced lung injury, the primary concern for the intensivists managing ARDS patients. Over the time, several trials have been done, which regularly improved and refined from each other. At the end, significant improvement in survival has been demonstrated in the most severe ARDS patients, at a threshold of 100-150 mmHg $\mathrm{PaO}_{2} / \mathrm{FiO}_{2}$ ratio. The effect of proning on survival cannot be predicted and seems unrelated with both severity of oxygenation impairment and oxygenation response to proning. The rate of complication is declining with the increase in centers expertise. The pressure sores are more frequent in prone and require a special attention. Prone position is a key component of lung protective mechanical ventilation and should be used as a first line therapy in association with low tidal volume and neuromuscular blocking agents in patients with severe ARDS.
\end{abstract}

Keywords: Acute respiratory distress syndrome (ARDS); mechanical ventilation; prone position; hypoxemia; ventilator induced lung injury

Submitted Apr 17, 2017. Accepted for publication May 10, 2017.

doi: $10.21037 /$ atm.2017.06.63

View this article at: http://dx.doi.org/10.21037/atm.2017.06.63

Prone positioning ARDS patients consists in placing the patient face down and continuing mechanical ventilation in this position for a long period of time, like 16 consecutive hours.

This strategy has eventually been found efficient to improve patient outcome in selected ARDS patients.

In this review, we will go over the rationale and then the evidence of using prone position in ARDS patients.

\section{Rationale}

The early reason that prompted clinicians to turn ARDS patient to prone was oxygenation improvement. This effect, sometimes dramatic (1), was observed in the large majority of patients. Therefore from the early onset the clinicians used proning to improve oxygenation. This effect resulted from a reduction in intra-pulmonary shunt. For the intra-pulmonary shunt to go down two possibilities do exist, either more ventilation in well perfused areas or less perfusion in poorly ventilated lung regions. The latter mechanism was considered as true as intuitively it was thought that the change in gravity direction will affect the lung perfusion in the same way, i.e., less perfusion towards dorsal lung regions, now non-dependent, in the prone position. Several experiments found that the dorsal lung regions when in the prone position still had the highest amount of blood flowing through them (2-8). Therefore, this unexpected finding argued against the second mechanism to explain the reduction in intra-pulmonary shunt. Therefore, better ventilation towards well perfused areas accounts for the common scenario to explain better oxygenation in prone (9).

With the recognition of ventilator-induced lung injury (VILI) it turned out that prone position was also able to modulate it. Animal studies, like that of Broccard et al. (10), demonstrated that prone position, as compared to supine 
position, attenuated and homogenized the distribution of lung injury across the ventral-to-dorsal direction when very high tidal volume were delivered in normal dogs. Lung strain was reduced and homogeneously distributed in prone (11). In humans, several lines of evidence argued in favor of the preventive role of proning against VILI. Papazian et al. found a reduction in the lung concentration of pro-inflammatory cytokines after 12 hours in prone as compared to supine position (12). CT studies consistently found that with prone the amount of overinflated lung mass declined and that of non or poorly aerated lung mass increased, indicating lung recruitment $(13,14)$. Cornejo et al. (14) extended these findings by showing that this result was present in patients with low or high potential of recruitment in the supine position, whatever they were receiving low or high PEEP. However, tidal recruitment/ decruitment, i.e., atelectrauma, was reduced in prone only in those patients with high recruitability and high PEEP in supine position. Finally a rodent study found that prone position was able to modulate the activation and expression of a kinase strongly involved in VUILI when rats were subjected to injurious ventilation (15). Furthermore in KO mice for this kinase injurious ventilation was associated with severe lung injury, which was attenuated in prone (15).

Homogenization of lung aeration (16), lung ventilation, lung perfusion, ventilation/perfusion ratio (17), stress and strain is the main effect of prone that accounts for both oxygenation improvement and VILI prevention.

Hemodynamic effect of prone position is an under investigated area and may have importance to explain the effect of prone on patient outcome. From the early use of proning (18) clinicians showed up the hemodynamic stability that contrasted with hemodynamic impairment with high PEEP they were using in case of severe hypoxemia. Circulatory failure in ARDS is frequent and complex (Figure 1). On one side the right ventricle systolic function can be impaired due to pulmonary hypertension resulting from hypoxemia, hypercapnia, vascular injury with thrombosis, overinflation (high PEEP and/or high tidal volume set at the ventilator) with increased resistance of alveolar vessels. Acute cor pulmonale, which occurred in almost $20-25 \%$ of ARDS patients (19), may result, at least partly, from pulmonary hypertension. Vieillard-Baron et al. (20) found that prone position for long sessions can reverse this phenomenon and, hence either prevent the occurrence or even treat these events. On another hand left ventricle systolic function can be impaired in ARDS patients from lung-heart interaction. Recently, Jozwiak et al. (21) found that cardiac index increased in prone position in those ARDS patients who were preload dependent (passive leg rising test) while supine and did not in those who were not. This suggests that prone position can shift the blood from unstressed to stressed abdominal vessels and, hence increase venous return.

\section{Evidence}

It is worth noting to have in mind that prone position story in ARDS patients was fed by a continuous improvement of pathophysiological knowledge and continuous refinement in the trials that were performed over the years. Given the numerous and impressive physiological benefits observed with prone position, a translation into patient outcome benefit was expected. The first trial by Gattinoni et al. (22) in almost 300 patients with acute lung injury and ARDS was disappointing as no effect on survival was found. It was followed by the first trial by Guerin et al. (23) on patients with acute hypoxemic respiratory failure. Again no difference in mortality was observed with prone as compared to the control group in supine. Several factors were discussed to explain these negative effects: short (7-8 hours proning sessions), cross over, no lung protective ventilation at this time (Table 1). The third trial by Mancebo et al. (24) introduced an important feature with much longer proning sessions (Table 1). The absolute difference in mortality amounted to $15 \%$, which did not reach statistical significance due to lack of power. The authors wrote that the rate of inclusion declined to such a level that they decided to stop the study before end. The second Italian trial (25) brought up new features: patients were stratified according to oxygenation into two groups (above or below $100 \mathrm{mmHg} \mathrm{PaO}_{2} / \mathrm{FiO}_{2}$ ratio), long proning sessions were employed. Again, no difference statistically significant between prone and supine groups (Table 1). However, these four trials were meta-analyzed at the individual data level (26). This study found no difference I survival in the whole population and in the subgroup of patients with $\mathrm{PaO}_{2} / \mathrm{FiO}_{2}$ greater than $100 \mathrm{mmHg}$. However, for the first time, significant better survival was found in patients with $\mathrm{PaO}_{2} / \mathrm{FiO}_{2}<100 \mathrm{mmHg}$ at the time of randomization. This individual meta-analysis confirmed a previous meta-analysis (27) done on grouped-data that included other trials. Finally, we designed a fifth trial with several specific features (28): we enrolled patients qualified as severe ARDS [this was before the Berlin definition (29)] with $\mathrm{PaO}_{2} / \mathrm{FiO}_{2}<150 \mathrm{mmHg}$ and PEEP of at least $5 \mathrm{cmH}_{2} \mathrm{O}$ and $\mathrm{FiO}_{2}$ of at least $60 \%$, who 


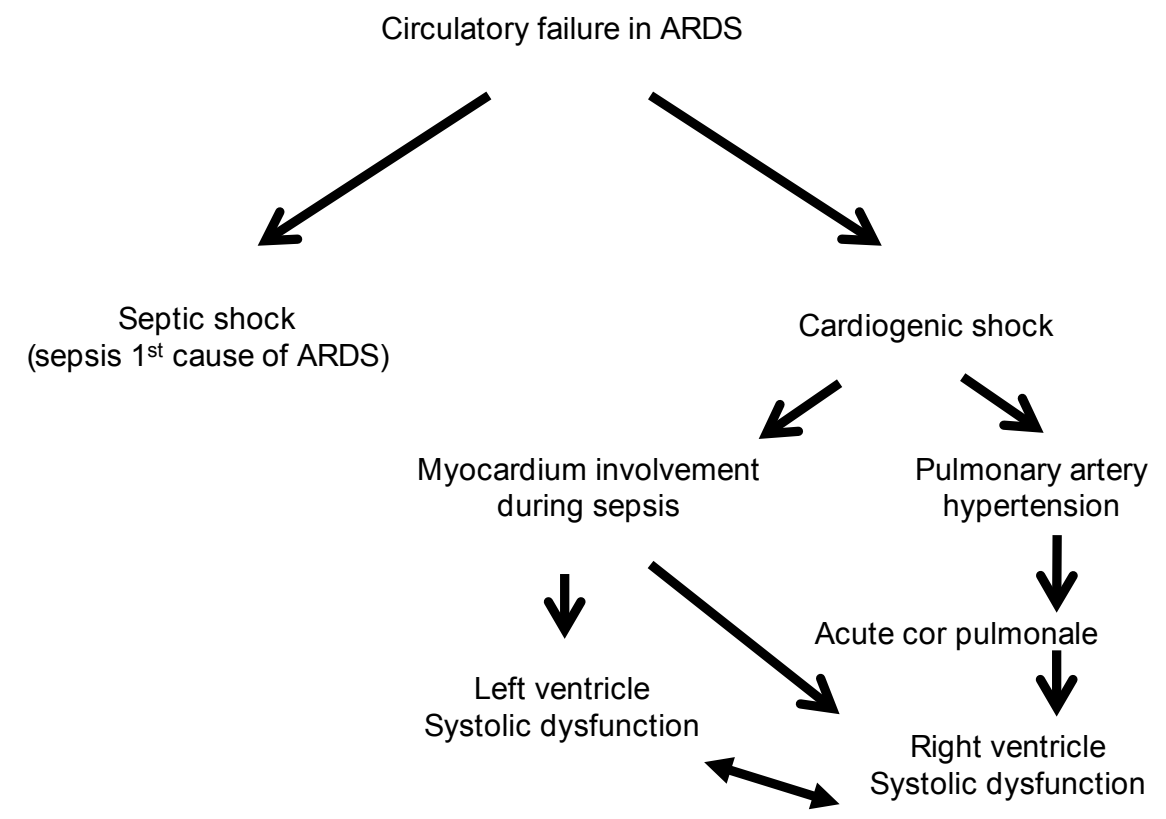

Ventricular interdependence

Figure 1 Mechanisms of acute circulatory failure in ARDS. ARDS, acute respiratory distress syndrome.

Table 1 Summary of the five largest trials on prone position

\begin{tabular}{|c|c|c|c|c|c|}
\hline \multirow{2}{*}{ Characteristics } & \multicolumn{5}{|c|}{ First author } \\
\hline & Gattinoni (22) & Guerin (23) & Mancebo (24) & Taccone (25) & Sud (28) \\
\hline No. of patients (SP/PP) & $152 / 152$ & $378 / 413$ & $60 / 76$ & $174 / 168$ & $229 / 237$ \\
\hline$\%$ of ARDS (SP/PP) & $93.3 / 94.7$ & $28 / 33.9$ & $100 / 100$ & $100 / 100$ & $100 / 100$ \\
\hline $\mathrm{PaO}_{2} / \mathrm{FiO}_{2}(\mathrm{mmHg})$ & 127 & 150 & 147 & 113 & 100 \\
\hline PEEP $\left(\mathrm{cmH}_{2} \mathrm{O}\right)$ & 10 & 8 & 12 & 10 & 10 \\
\hline $\begin{array}{l}\text { PP session duration (average hours per } \\
\text { session) }\end{array}$ & 7 & 8 & 17 & 18 & 17 \\
\hline Mortality (SP/PP) (\%) & $25 / 21.1$ & $31.5 / 32.4$ & $58 / 43$ & $32.8 / 31$ & $32.8 / 16$ \\
\hline
\end{tabular}

SP, supine position; PP, prone position; MBW, measured body weight; PBW, predicted body weight; PEEP, positive end-expiratory pressure.

exhibited these criteria after a 12-24 stabilization period, no cross over was allowed except for life-threatening hypoxemia, strict lung protective ventilation was applied, neuromuscular blockade was used in both groups, the first proning session in the prone group was done within the hour after randomization, the proning sessions lasted at least 16 consecutive hours, predetermined criteria for stopping proning were defined, participating ICU had large experience with proning for many years. With this protocol, we obtained a significant reduction in mortality from 32.8 in the supine group to $16 \%$ in the prone group at day 28 after randomization, which was confirmed at day $90(41 \%$ vs. $23.6 \%$, respectively).

Further meta-analyses including the above Proseva trial confirmed the beneficial effect of prone position in ARDS patients (30-33). Clearly prone position benefit to 
the most severe ARDS patients (34), even though some meta-analysis suggested the benefit was found regardless the oxygenation level (33). Prone position, lower tidal volume (35) and early use of neuromuscular blocking agents (36) are to date the three only interventions that have proved benefit in ARDS (37). The mechanisms by which ARDS patients survival improved in prone basically stem from the physiological effects reviewed above. Another mechanism was also suggested, namely the prevention of ventilator-associated pneumonia. Indeed, prone is well known to promote respiratory secretions in large amount and this effect could contribute to facilitate drainage and, hence prevent pneumonia. However, in the Proseva trial the rate of ventilator-associated pneumonia was similar in both groups (38). Interestingly, neither the level of hypoxemia at the time of randomization (39) nor the oxygenation or the $\mathrm{PaCO} 2$ response to the first prone position session (40) were associated with patient survival. The role of driving pressure, the current stronger predictor of mortality in ARDS (41), is under investigation. We recently observed that driving pressure share the same information as plateau pressure to predict survival in ARDS patients receiving lung protective mechanical ventilation (42).

However, in routine practice the rate of use of prone position has been found as low as $16 \%$ in severe ARDS patients in the recent large prospective epidemiologic Lung safe study (43). Clinicians are reluctant to use this procedure due to its complexity, risk of complications, uncertainty regarding its real effects. The rate of complications affecting airways was, however, not significantly different between the two groups in the Proseva trial. Prone position can also be used in patients under ECMO, indicating that once every effort has been made in the ICU with the caregivers this procedure can be done routinely and safely. It should be mentioned that pressure sores are still an issue. These are more frequent in prone than in supine and preventive means should be done in this area.

\section{Conclusions}

Prone position is a key component of lung protective mechanical ventilation and should be used as a first line therapy in association with low tidal volume and neuromuscular blocking agents in patients with severe ARDS.

\section{Acknowledgements}

(c) Annals of Translational Medicine. All rights reserved.
None.

\section{Footnote}

Conflicts of Interest: The author has no conflicts of interest to declare.

\section{References}

1. Mure M, Martling CR, Lindahl SG. Dramatic effect on oxygenation in patients with severe acute lung insufficiency treated in the prone position. Crit Care Med 1997;25:1539-44.

2. Glenny RW, Lamm WJ, Albert RK, et al. Gravity is a minor determinant of pulmonary blood flow distribution. J Appl Physiol (1985) 1991;71:620-9.

3. Glenny RW, Lamm WJ, Bernard SL, et al. Selected contribution: redistribution of pulmonary perfusion during weightlessness and increased gravity. J Appl Physiol (1985) 2000;89:1239-48.

4. Glenny RW, Polissar L, Robertson HT. Relative contribution of gravity to pulmonary perfusion heterogeneity. J Appl Physiol (1985) 1991;71:2449-52.

5. Glenny RW, Robertson HT. Spatial distribution of ventilation and perfusion: mechanisms and regulation. Compr Physiol 2011;1:375-95.

6. Hlastala MP, Bernard SL, Erickson HH, et al. Pulmonary blood flow distribution in standing horses is not dominated by gravity. J Appl Physiol (1985) 1996;81:1051-61.

7. Walther SM, Domino KB, Glenny RW, et al. Pulmonary blood flow distribution in sheep: effects of anesthesia, mechanical ventilation, and change in posture.

Anesthesiology 1997;87:335-42.

8. Walther SM, Domino KB, Glenny RW, et al. Positive endexpiratory pressure redistributes perfusion to dependent lung regions in supine but not in prone lambs. Crit Care Med 1999;27:37-45.

9. Rohdin M, Petersson J, Mure M, et al. Distributions of lung ventilation and perfusion in prone and supine humans exposed to hypergravity. J Appl Physiol (1985) 2004;97:675-82.

10. Broccard A, Shapiro RS, Schmitz LL, et al. Prone positioning attenuates and redistributes ventilator-induced lung injury in dogs. Crit Care Med 2000;28:295-303.

11. Valenza F, Guglielmi M, Maffioletti $M$, et al. Prone position delays the progression of ventilator-induced lung injury in rats: does lung strain distribution play a role? Crit Care Med 2005;33:361-7.

12. Papazian L, Gainnier M, Marin V, et al. Comparison 
of prone positioning and high-frequency oscillatory ventilation in patients with acute respiratory distress syndrome. Crit Care Med 2005;33:2162-71.

13. Galiatsou E, Kostanti E, Svarna E, et al. Prone position augments recruitment and prevents alveolar overinflation in acute lung injury. Am J Respir Crit Care Med 2006;174:187-97.

14. Cornejo RA, Diaz JC, Tobar EA, et al. Effects of prone positioning on lung protection in patients with acute respiratory distress syndrome. Am J Respir Crit Care Med 2013;188:440-8.

15. Park MS, He Q, Edwards MG, et al. Mitogen-activated protein kinase phosphatase-1 modulates regional effects of injurious mechanical ventilation in rodent lungs. Am J Respir Crit Care Med 2012;186:72-81.

16. Gattinoni L, Pelosi P, Vitale G, et al. Body position changes redistribute lung computed-tomographic density in patients with acute respiratory failure. Anesthesiology 1991;74:15-23.

17. Richter T, Bellani G, Scott Harris R, et al. Effect of prone position on regional shunt, aeration, and perfusion in experimental acute lung injury. Am J Respir Crit Care Med 2005;172:480-7.

18. Gaussorgues P, Chazot C, Vedrinne C, et al. Improvement of diffuse pneumopathies by ventilation in prone position. Presse Med 1987;16:1200.

19. Boissier F, Katsahian S, Razazi K, et al. Prevalence and prognosis of cor pulmonale during protective ventilation for acute respiratory distress syndrome. Intensive Care Med 2013;39:1725-33.

20. Vieillard-Baron A, Charron C, Caille V, et al. Prone positioning unloads the right ventricle in severe ARDS. Chest 2007;132:1440-6.

21. Jozwiak M, Teboul JL, Anguel N, et al. Beneficial hemodynamic effects of prone positioning in patients with acute respiratory distress syndrome. Am J Respir Crit Care Med 2013;188:1428-33.

22. Gattinoni L, Tognoni G, Pesenti A, et al. Effect of prone positioning on the survival of patients with acute respiratory failure. N Engl J Med 2001;345:568-73.

23. Guerin C, Gaillard S, Lemasson S, et al. Effects of systematic prone positioning in hypoxemic acute respiratory failure. JAMA 2004;292:2379-87.

24. Mancebo J, Fernandez R, Blanch L, et al. A multicenter trial of prolonged prone ventilation in severe acute respiratory distress syndrome. Am J Respir Crit Care Med 2006;173:1233-9.

25. Taccone $\mathrm{P}$, Pesenti A, Latini R, et al. Prone positioning in patients with moderate and severe acute respiratory distress syndrome: a randomized controlled trial. JAMA 2009;302:1977-84.

26. Guérin C, Reignier J, Richard JC, et al. Prone positioning in severe acute respiratory distress syndrome. $\mathrm{N}$ Engl J Med 2013;368:2159-68.

27. Gattinoni L, Carlesso E, Taccone P, et al. Prone positioning improves survival in severe ARDS: a pathophysiologic review and individual patient metaanalysis. Minerva Anestesiol 2010;76:448-54.

28. Sud S, Friedrich JO, Taccone P, et al. Prone ventilation reduces mortality in patients with acute respiratory failure and severe hypoxemia: systematic review and metaanalysis. Intensive Care Med 2010;36:585-99.

29. ARDS Definition Task Force, Ranieri VM, Rubenfeld GD, et al. Acute respiratory distress syndrome: the Berlin Definition. JAMA 2012;307:2526-33.

30. Beitler JR, Shaefi S, Montesi SB, et al. Prone positioning reduces mortality from acute respiratory distress syndrome in the low tidal volume era: a meta-analysis. Intensive Care Med 2014;40:332-41.

31. Sud S, Friedrich JO, Adhikari NK, et al. Effect of prone positioning during mechanical ventilation on mortality among patients with acute respiratory distress syndrome: a systematic review and meta-analysis. CMAJ 2014;186:E381-90.

32. Bloomfield R, Noble DW, Sudlow A. Prone position for acute respiratory failure in adults. Cochrane Database Syst Rev 2015;11:CD008095.

33. Lee JM, Bae W, Lee YJ, et al. The efficacy and safety of prone positional ventilation in acute respiratory distress syndrome: updated study-level meta-analysis of 11 randomized controlled trials. Crit Care Med 2014;42:1252-62.

34. Ferguson ND, Fan E, Camporota L, et al. The Berlin definition of ARDS: an expanded rationale, justification, and supplementary material. Intensive Care Med 2012;38:1573-82.

35. Acute Respiratory Distress Syndrome Network, Brower RG, Matthay MA, et al. Ventilation with lower tidal volumes as compared with traditional tidal volumes for acute lung injury and the acute respiratory distress syndrome. N Engl J Med 2000;342:1301-8.

36. Papazian L, Forel JM, Gacouin A, et al. Neuromuscular blockers in early acute respiratory distress syndrome. $\mathrm{N}$ Engl J Med 2010;363:1107-16.

37. Tonelli AR, Zein J, Adams J, et al. Effects of interventions on survival in acute respiratory distress syndrome: an 
umbrella review of 159 published randomized trials and 29 meta-analyses. Intensive Care Med 2014;40:769-87.

38. Ayzac L, Girard R, Baboi L, et al. Ventilator-associated pneumonia in ARDS patients: the impact of prone positioning. A secondary analysis of the PROSEVA trial. Intensive Care Med 2016;42:871-8.

39. Guérin C, Reignier J, Richard JC, et al. Prone positioning in severe acute respiratory distress syndrome. $\mathrm{N}$ Engl J Med 2013;368:2159-68.

40. Albert RK, Keniston A, Baboi L, et al. Prone positioninduced improvement in gas exchange does not predict improved survival in the acute respiratory distress

Cite this article as: Guérin C. Prone positioning acute respiratory distress syndrome patients. Ann Transl Med 2017;5(14):289. doi: 10.21037/atm.2017.06.63 syndrome. Am J Respir Crit Care Med 2014;189:494-6.

41. Amato MB, Meade MO, Slutsky AS, et al. Driving pressure and survival in the acute respiratory distress syndrome. $\mathrm{N}$ Engl J Med 2015;372:747-55.

42. Guérin C, Papazian L, Reignier J, et al. Effect of driving pressure on mortality in ARDS patients during lung protective mechanical ventilation in two randomized controlled trials. Crit Care 2016;20:384.

43. Bellani G, Laffey JG, Pham T, et al. Epidemiology, Patterns of Care, and Mortality for Patients With Acute Respiratory Distress Syndrome in Intensive Care Units in 50 Countries. JAMA 2016;315:788-800. 